\title{
Vasculite leucocitoclástica e infecção crónica por Hepatite B
}

\section{Leukocytoclastic vasculitis and chronic infection by hepatitis $B$}

\author{
Mário Pires, Magda Sousa, Ana Montez, Ivo Julião \\ ${ }^{1}$ Serviço de Medicina Interna, Centro Hospitalar do Baixo Vouga - Aveiro. Portugal
}

\section{Resumo}

Os autores apresentam o caso clínico de uma doente de 79 anos, internada para estudo de uma vasculite, cuja investigação etiológica nos levou a ponderar a associação com hepatite B crónica. A vasculite leucocitoclástica pode ter variadas etiologias. A associação com hepatite vírica é mais frequente com a hepatite $C$, havendo no entanto alguns casos relatados sobre a associação à hepatite $\mathrm{B}$. A etiologia vírica tem de ser sempre considerada nestas situações, pois a resolução do quadro pode passar pelo tratamento da patologia de base.

Palavras chave: Vasculitis leucocitoclàstica. Hepatitis B crònica. Crioglobulinas.

\section{Introdução}

As vasculites de pequenos vasos englobam um grupo heterogéneo de doenças como a vasculite leucocitoclástica, a granulomatose de Wegener, a síndrome de Churg-Strauss e a púrpura de Henoch Schönlein. Na vasculite leucocitoclástica ocorre depósito de imunocomplexos e infiltrado inflamatório com fragmentação de neutrófilos localizados na parede vascular, além de presença de necrose fibrinóide.

Afecta principalmente a pele, mas 0 envolvimento sistémico pode ocorrer em cerca de $50 \%$ dos casos, com atingimento renal, articular, pulmonar, muscular, cardíaco, gastrintestinal e dos nervos periféricos ${ }^{1,2}$. Quanto à etiologia, esta entidade

\begin{abstract}
The authors present a case report of a 79 year old patient who was admitted for the study of vasculitis, whose etiological investigation led us to consider the association with chronic hepatitis B infection. Leucocytoclastic vasculitis may have varied etiologies. The association with viral hepatitis is more common with hepatitis C, but there are some cases reported about the association with hepatitis $\mathrm{B}$. The viral etiology must always be considered in such situations because the case resolution can implicate the treatment of the underlying disease.

Keywords: Leucocytoclastic vasculitis. Chronic hepatitis B. Cryoglobulin
\end{abstract}

pode ser idiopática ou estar relacionada com o uso de medicamentos, infecções e neoplasias, podendo ser também uma manifestação de algumas colagenoses ${ }^{3}$. A associação com a infecção com hepatite B é uma possibilidade sendo muito pouco comum.

\section{Caso Clínico}

Apresentamos o caso de uma paciente de 79 anos que desenvolveu ao longo de duas semanas um exantema purpúrico, palpável, não pruriginoso, nos membros inferiores. Sem queixas de artralgias, dores abdominais ou febre.

Apresentava lesões de púrpura palpável, simétricas, envolvendo ambos os membros inferiores, até às coxas (Fig. 1). Apresentava

Figura 1. Lesões de vasculite leucocitoclástica, no primeiro dia de internamento.

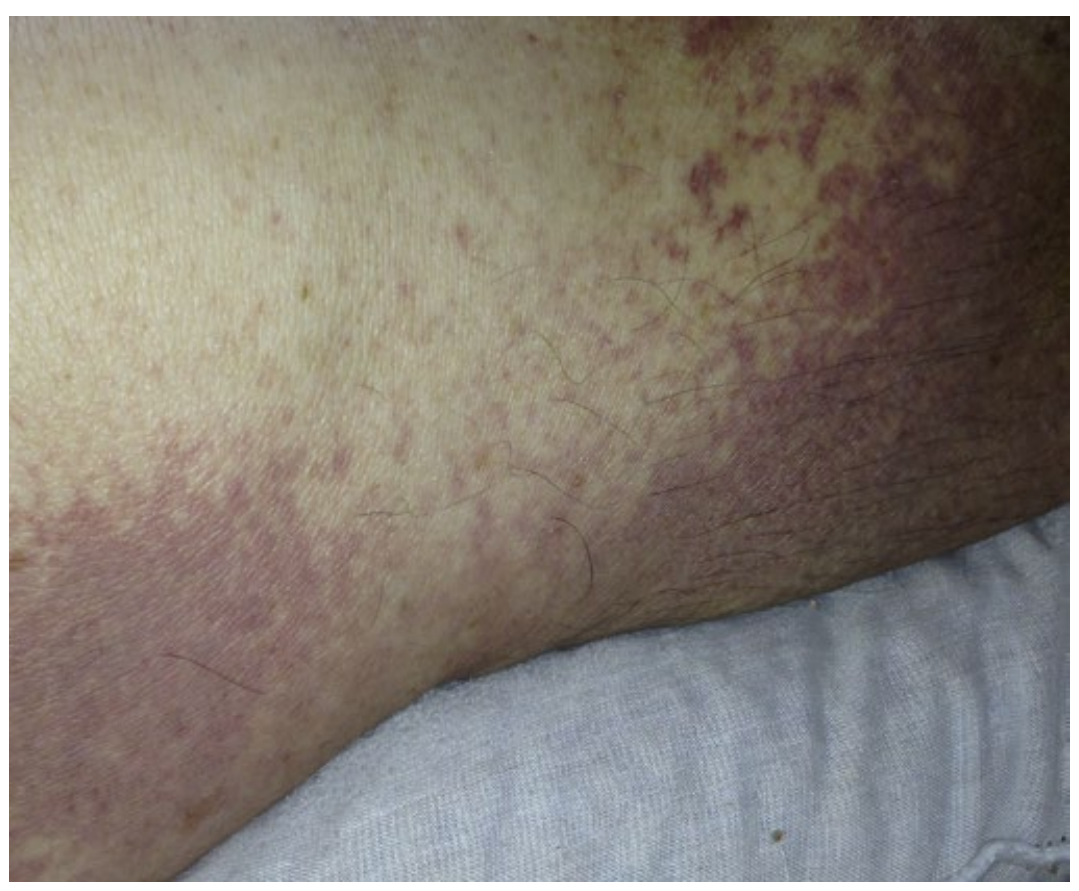


também hiperpigmentação sugestiva de insuficiência venosa crónica. Sem alteração da coloração cutânea em outros locais, abdómen indolor e sem massas palpáveis. Tratava-se de uma doente com antecedentes de diabetes mellitus tipo 2, dislipidémia, insuficiência venosa crónica, hipertensão arterial e gonartrose bilateral, estava medicada com sinvasatina, losartan+hidroclorotiazida, amlodipina, nevibolol, metformina+sitagliptina, ácido alendrónico e cloxazolam. Nenhum destes medicamentos tinha sido introduzido recentemente. Logo no serviço de urgência foi iniciada prednisolona na dose de $1 \mathrm{mg} / \mathrm{kg} / \mathrm{dia}(80 \mathrm{mg})$.

Do estudo analítico realizado, de salientar a alteração da função renal, com proteinúria em amostra de urina de $24 \mathrm{~h}$. A maioria dos restantes parâmetros era normal, nomeadamente hemograma e proteinograma electroforético. Do estudo imunológico, anti-dsDNA, pANCA, cANCA e os anticorpos anti-nucleares foram negativo. 0 factor reumatoide foi positivo e estudo do complemento mostrou um valor baixo do componente C4 com C3 normal. A pesquisa de crioglobulinas foi positiva, no entanto não dispomos de resultado quantitativo (Tabela 1).

0 resultado da biópsia cutânea confirmou tratar-se de vasculite leucocitoclástica (". . . vasculite leucocitoclástica dos pequenos vasos da derme...."). Na sequência do estudo etiológico, foram realizadas as serologias para sífilis, VIH, Hepatite C e Hepatite B. Os primeiros resultados vieram negativos, mas a serologia do vírus da hepatite B foi sugestiva de infecção crónica. (Tabela 2)

Neste contexto, realizou ecografia abdominal (que mostrou um fígado ligeiramente aumentado de volume, hiperreflectivo, sugestivo de infiltração esteatósica), biópsia hepática (“...lesões de hepatite crónica, compatível com etiologia vírica (...) ausência de fibrose portal (...) pesquisa de antigénios HBs positiva...") e doseamento da carga viral do vírus da Hepatite B (Tabela 2).

Após os primeiros dias de corticoterapia foi visível a melhoria das lesões cutâneas (Fig. 2), tendo posteriormente desaparecido na totalidade. Actualmente (cerca de 6 meses após o quadro inicial) a doente é seguida em consultas de infecciologia e medicina interna, a dose de corticoide foi reduzida progressivamente até à suspensão, sem agravamento da situação clínica, nem novas lesões cutâneas. Foi efectuada nova avaliação renal, com melhoria da função e da proteinúria (Tabela 1).

\section{Discussão}

As vasculites representam um grupo muito heterogéneo de doenças, quer quanto à sua gravidade, afectação de órgãos e etiologia. A vasculite leucocitoclástica é idiopática em 50\% dos casos, mas pode ser secundária a doenças infecciosas, auto-imunes, neoplásicas ou induzida por fármacos ${ }^{3}$.

$\mathrm{Na}$ investigação, as infecções víricas devem ser sempre consideradas, principalmente quando não há outros factores etiológicos aparentes.

As crioglobulinémias podem ser do tipo I, II ou \|\|$^{4}$. A criogIobulinémia mista (tipo II ou III), representa 80\% dos casos, estando relacionada com estados inflamatórios crónicos, nomeadamente doenças autoimunes e infecções víricas, sendo a situação mais provável neste caso. Já a crioglobulinémia do tipo I associa-se com doenças linfoproliferativas, havendo produção de uma crioglobulina monoclonal.

As crioglobulinas podem estar presentes em casos de vasculite leucocitoclástica, especialmente quando associados a infecção (hepatite $C$, hepatite $B$, endocardite) ${ }^{5}$. A vasculite leucocitoclástica por depósitos de crioglobulinas é frequentemente associada a infecção pelo vírus da hepatite $C^{6,7}$, sendo a sua relação com a infecção pelo vírus da hepatite $B$ é algo controversa, havendo no entanto alguns casos relatados ${ }^{8,9,10}$. A presença de factor reumatóide positivo ${ }^{11}$ e a hipocomplementémia são dados a favor da formação de imunocomplexos ${ }^{12}$. A infecção por hepatite $B$ está relacionada mais frequentemente com poliarterite nodosa (PAN), estando presente em 10 a $54 \%$ dos casos de PAN ${ }^{6}$.

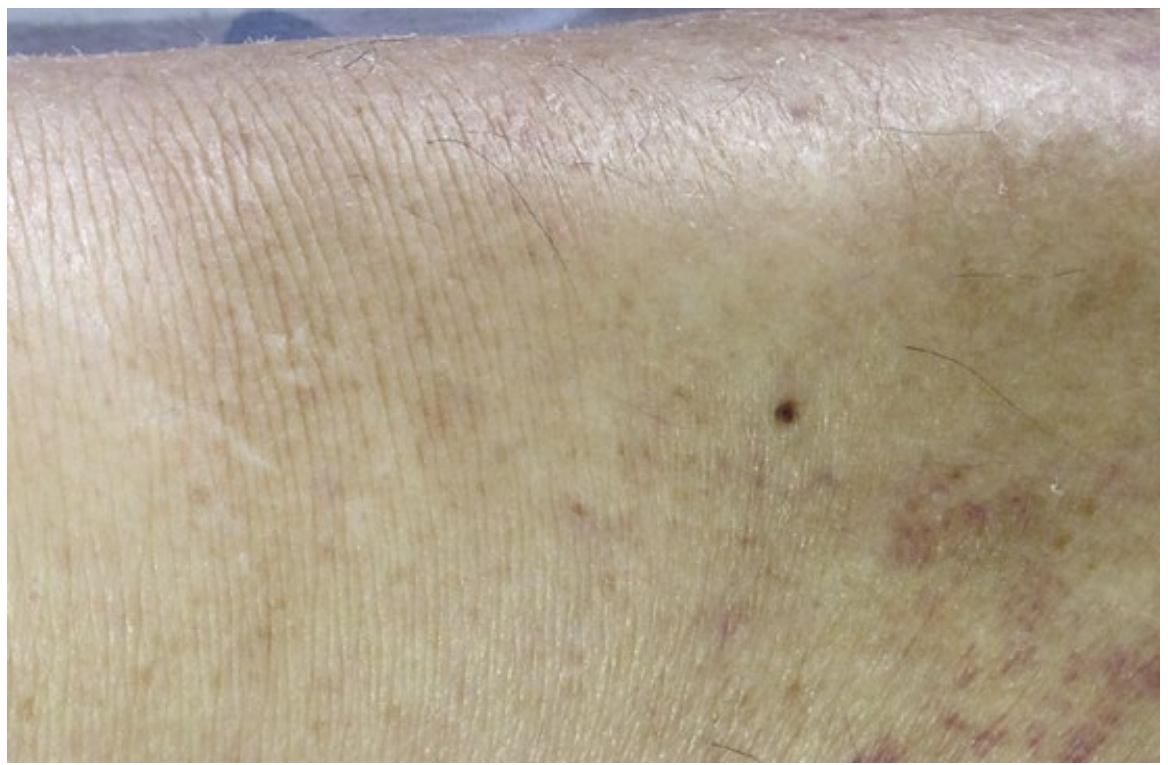


Tabela 1. Parâmetros analíticos

\begin{tabular}{|ll|}
\hline Internamento & $11 \mathrm{~g} / \mathrm{dl}$ \\
Hemoglobina & $12.00 \times 109 / \mathrm{L}$ \\
Leucócitos & $10.20 \times 109 / \mathrm{L}$ \\
Neutrófilos & $1,9 \mathrm{mg} / \mathrm{dl}$ \\
Creatinina & $75,83 \mathrm{ml} / \mathrm{min}$ \\
Clearance Creatinina & $78 \mathrm{mg} / \mathrm{dl}$ \\
Ureia & 30 \\
TGO & 50 \\
TGP & 242 \\
LDH & Negativo \\
Anti-dsDNA & $1 / 160$ \\
ANA & $168 \mathrm{U} / \mathrm{ml}$ \\
Factor Reumatoide & $137 \mathrm{mg} / \mathrm{dl}$ \\
C3 & $2 \mathrm{mg} / \mathrm{dl}$ \\
C4 & Negativo \\
pANCA & Negativo \\
CANCA & $1080 \mathrm{mg}$ \\
Proteinúria 24h & \\
\hline Consulta & \\
Creatinina & $0,7 \mathrm{mg} / \mathrm{dl}$ \\
Proteinúria 24h & $258 \mathrm{mg} / \mathrm{dl}$ \\
ANA & $<1 / 160$ \\
C4 & $29 \mathrm{mg} / \mathrm{dl}$ \\
\hline
\end{tabular}

Tabela 2. Serologias víricas e carga viral vírus hepatite $B$

\begin{tabular}{|lc|}
\hline anti-HBs & - \\
agHBs & + \\
antiHBC & + \\
anti-HBc lgM & - \\
anti-HBe & + \\
agHBe & - \\
Carga Viral (Ul/ml) & 9000 \\
\hline
\end{tabular}

Na maioria dos casos a vasculite leucocitoclástica é limitada à pele, mas alguns pacientes têm lesões vasculares sistémicas, principalmente com atingimento renal, muscular, articular, do trato gastrointestinal e dos nervos periféricos ${ }^{1,2}$.

$\mathrm{Na}$ generalidade, o tratamento da vasculite deve ser dirigido ao processo patológico subjacente, sempre que possível. Na PAN associada a hepatite B crónica, está descrita a melhoria do quadro após tratamento com lamivudina e interferão lffa $^{13}$. A carga viral da doente é baixa e a histologia hepática não mostrou fibrose, pelo que foi considerado não ter indicação para iniciar tratamento para a hepatite B. De acordo com a gravidade e atingimento de órgãos alvo, as condutas terapêuticas podem passar pelo seguimento sem introdução de qualquer atitude terapêutica, até à utilização de imunossupressores ${ }^{11}$. Nesta doente foi iniciado ab initio corticoterapia sistémica, com melhoria progressiva das lesões. Podia-se ter assumido uma atitude expectante, mas devido à alteração da função renal (apesar de eventualmente poderem ser por nefropatia diabética), optou-se por introduzir logo terapêutica.

No caso apresentado temos então uma biópsia de pele característica de vasculite leucocitoclástica, pesquisa de crioglobulinas positiva e foi documentada infecção crónica pelo vírus da hepatite B. Uma vez que não houve possibilidade de efectuar a pesquisa de depósitos de componentes virais na histologia da pele, não se pode estabelecer definitivamente uma relação de causalidade entre a infecção pelo vírus da hepatte $B$ e a vasculite. No entanto não foram identificadas outras causas para a situação, pelo que, a hipótese é plausível. Será importante o seguimento a longo prazo desta doente, pois esta poderá também ser a manifestação inicial de outra entidade, nomeadamente doença auto-imune ou com menor probabilidade doença linfoproliferativa.

\section{Conclusão}

As causas das vasculites são vastas, a sua procura e identificação pode permitir um tratamento mais dirigido e, consequentemente, mais eficaz e com menos efeitos secundários. Com este caso, pretendemos alertar para a importância do estudo etiológico destas entidades e da necessidade de excluir sempre infecção vírica. Além disso, apesar de na maioria dos casos os resultados irem de encontro às descrições clássicas, devemos ter sempre presente etiologias menos frequentes.

\section{Referências}

1. Brandt HRC, Arnone M, et al. Vasculite cutânea de pequenos vasos: etiologia, patogênese, classificação e critérios diagnósticos - Parte I. An Bras Dermatol. 2007;82(5)387406.

2. Arvan ME, Brodell RT. A palpable clue to vasculitis. Post Grad Med 1999;105:229-32.

3. Bonnefoy M, Claudy A L. Etude prospective de facteurs associes aux vascularites leucocytoclasiques. Ann Dermatol Venereol, 1988;115: 27-32

4. Takada S, Shimizu T, et al. Cryoglobulinemia (review). Mol Med Rep. 2012 Jul;6(1):3-8

5. Baerlecken NT, Schmidt RE. Essential mixed cryoglobulinemia type III with leukocytoclastic vasculitis: remission by rituximab. Clin Rheumatol. 2013 Mar;32 Suppl 1:S1920.

6. Cristina C. Belizna, Mohamed A. Hamidou, et al. Infection and vasculitis. Rheumatology (2009) 48 (5): 475-482

7. Vergani D, Mieli-Vergani G. Autoimmune manifestations in viral hepatitis. Semin Immunopathol. 2013 Jan;35(1):73-85.

8. Michele Barone, Raffaele Licinio, et al. Lesson from an intriguing case of cryoglobulinemia. World J Gastroenterol. 2013 January 14; 19(2): 304-306.

9. Levo Y, Gorevic PD, et al. Association between hepatitis B virus and essential mixed cryoglobulinemia. N Engl J Med 1977;296:1501-4.

10. Levo Y. Hepatitis B virus and essential mixed cryoglobulinemia. Ann Intern Med 1981;94:282.

11. Ferri C, Mascia MT. Cryoglobulinemic vasculitis. Curr Opin Rheumatol. 2006;18:54-63.

12. Diagnostic significance of hypocomplementemia. Hebert LA, Cosio FG, Neff JC. Kidney Int. 1991 May;39(5):811-21.

13. D. Maclachlan, M. Battegay, et al. Successful treatment of hepatitis B-associated polyarteritis nodosa with a combination of lamivudine and conventional immunosuppressive therapy: a case report. Rheumatology (2000) 39 (1): 106-108. 